This item was submitted to Loughborough's Research Repository by the author.

Items in Figshare are protected by copyright, with all rights reserved, unless otherwise indicated.

\title{
The passage of deforming drops through a slotted microfilter
}

PLEASE CITE THE PUBLISHED VERSION

http://dx.doi.org/10.1205/cherd06008

\section{PUBLISHER}

Elsevier () Institution of Chemical Engineers

VERSION

AM (Accepted Manuscript)

LICENCE

CC BY-NC-ND 4.0

REPOSITORY RECORD

Kosvintsev, S.R., P.D. Sutrisna, lain W. Cumming, R.G. Holdich, and G. Mason. 2012. "The Passage of Deforming Drops Through a Slotted Microfilter”. figshare. https://hdl.handle.net/2134/9305. 
This item was submitted to Loughborough's Institutional Repository (https://dspace.lboro.ac.uk/) by the author and is made available under the following Creative Commons Licence conditions.

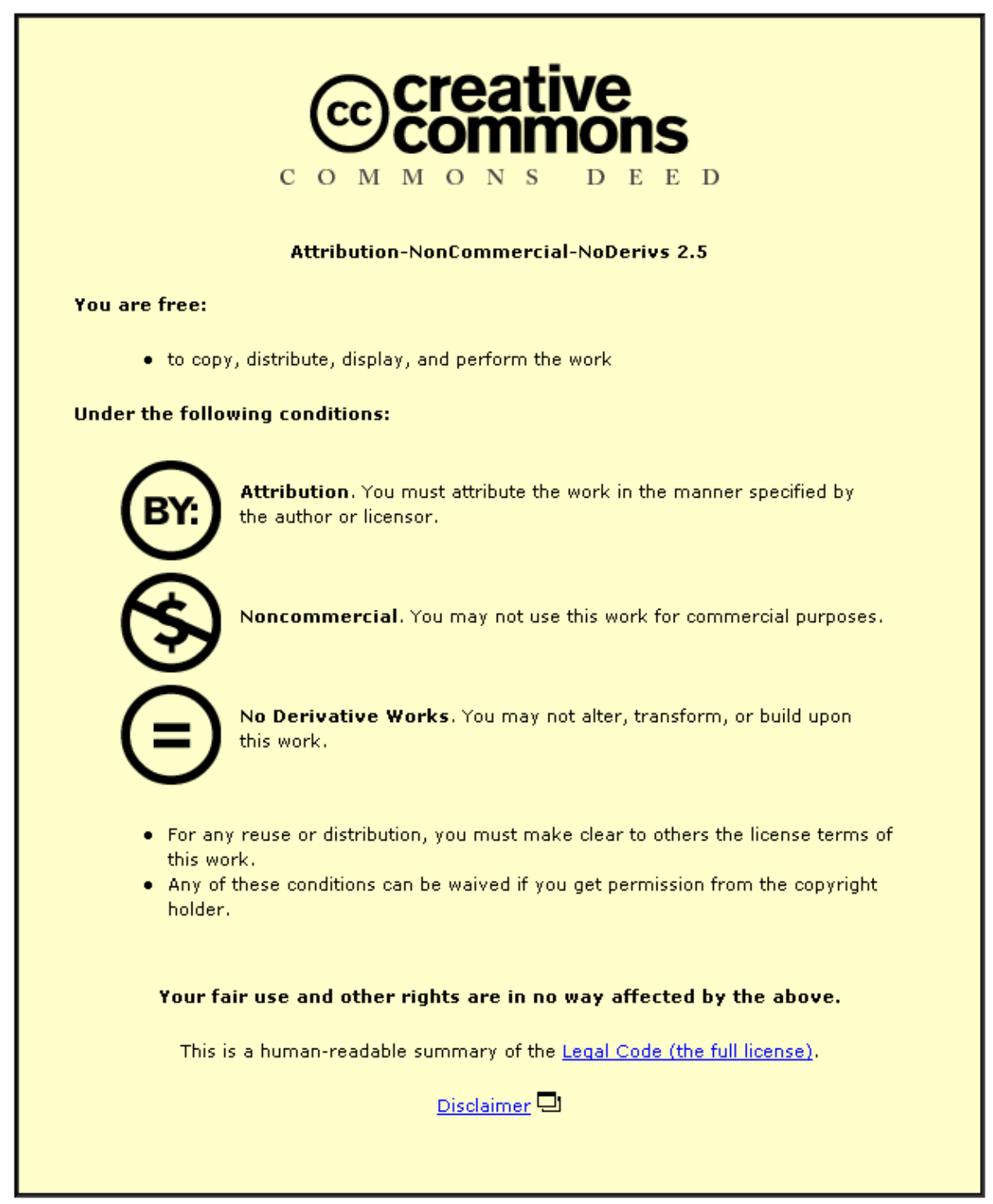

For the full text of this licence, please go to: http://creativecommons.org/licenses/by-nc-nd/2.5/ 


\title{
The Passage of Deforming Drops Through A Slotted Microfilter
}

\author{
S.R. Kosvintsev, P.D. Sutrisna I.W. Cumming, R.G. Holdich and G. Mason \\ Department of Chemical Engineering, Loughborough University, Leicestershire, \\ LE11 3TU, U.K.
}

Abstract (To do: amend nomenclature IWC, check SRK)

In the flow of a deforming drop through a slotted pore, such as during the microfiltration of oil drops suspended in water, the mechanism for the convection of the oil drops is liquid drag caused by permeate flow through the filter. If the slot is designed to have a converging section, before the position of minimum slot width, then it is possible to evaluate the force on the drop from the liquid drag and to observe the position at which the drop comes to rest within the converging slot. This equilibrium position is established due to a balance of forces between the liquid drag and the force required to deform the drop to create a larger surface area as the drop becomes less spherical. Experimental measurements are presented for a bubble deforming within an aqueous flow field and a paraffin oil flow field, together with results for the motion of a paraffin oil drop within an aqueous flow field. The data is correlated using a ratio of drop to channel diameter (analogous to slot width) against superficial liquid velocity. Different curves are provided depending only on the physical properties of the fluids used. An analytical mathematical development predicts these curves to a good degree of reliability, which can then be used to predict the oil drop size that is $100 \%$ rejected during the filtration of oil drops on slotted microfiltration membranes. Experimental evidence is presented to support the prediction using the filtration of a crude oil on a slotted microfilter with a minimum pore width of 5 microns.

keywords

membrane, oil, modelling, pore 


\section{INTRODUCTION}

The removal of stable oil drops dispersed in water is a problem that arises in a number of industries. Oil removal is usually required because of the environmental problems associated with the discharge of oily water. A very important source of dispersed oil in water is that of Produced Water, which is associated with oil production. As oil fields matures the amount of PW increases and this water may either be reinjected to the reservoir, or in the case of off-shore platforms, discharged overboard to the sea. The quantities of PW may range from 860 to $27000 \mathrm{~m}^{3}$ day $^{-1}$ (Hargreaves and Silvester, 1990). The discharge limit for the amount of oil disposed of to sea from offshore oilfields has been set at $40 \mathrm{mg} \mathrm{l}^{-1}$ (International Maritime Organisation, 1972). This limit is being reduced to $30 \mathrm{mg} \mathrm{l}^{-1}$ in 2006 with the additional constraint that the total oil discharged with the produced water should be $15 \%$ less than that discharged in 2000.

At present, the oil content of the water is controlled by the use of a primary separator often followed by a hydrocyclone. The oil drops may be encouraged to coalesce to form larger drops by the addition of chemical agents. The hydrocyclone efficiency declines with reducing droplet size and their performance is poor below $10 \mu \mathrm{m}$.

Several different techniques have been investigated to try and reduce the oil content of the produced water. A number of workers have studied ultrafiltration to reduce the oil content and these have been successful in the treatment of low volume effluents such as cutting oils. However, for the much higher throughputs required for processing PW the fluxes achieved have been often less than $1001 \mathrm{~m}^{-2} \mathrm{~h}^{-1}$ (Rautenbach \& Albrecht (1989), Lipp et al (1988), Lin \& Lan (1998) which would result in large membrane area. In an attempt to improve the achievable flux microfiltration has been tested as a means to remove the suspended oil. It has been 
found that, despite the apparently more permeable membrane, again the filtrate flow is generally at, or below, $100 \mathrm{l} \mathrm{m}^{-2} \mathrm{~h}^{-1}$ (Koltuniewicz et al (1995), Koltuniewicz \& Field (1996), Mueller et al (1997), Wang et al (2000), Madaeni \& Yeganeh (2003)).

It has been suggested by Holdich et al (1998) that many microfilter membranes operate with significant depth filtration and, therefore, suffer from internal fouling, whilst true surface filters with pores passing directly from one side to the other are less common. Significant internal fouling being the cause of irreversible permeate flux decline. The work using a tubular surface microfilter with pore diameters of 6.8 $\mu \mathrm{m}$ and $8 \mu \mathrm{m}$, and separation enhanced by spinning the liquid within the tube, enabled fluxes of over $200 \mathrm{l} \mathrm{m}^{-2} \mathrm{~h}^{-1}$ to be maintained. More recently, Cumming et al (2000) using a microfilter with $5 \mu \mathrm{m}$ slotted pores showed that much higher fluxes could be achieved, between 1000 to $20001 \mathrm{~m}^{-2} \mathrm{~h}^{-1}$, when filtering an oil dispersion containing $1000 \mathrm{mg} \mathrm{l}^{-1}$ oil with a rejection of $50 \%$ for oil drops of $2 \mu \mathrm{m}$ with total rejection at $9.5 \mu \mathrm{m}$. This large improvement in achievable flux suggested that the mechanism of filtration using filters with circular pores is very different to that using slotted pores whilst the rejection of the deformable drops can be maintained. Slotted pore microfiltration has become a topic of great interest in fields other than oil recovery, with papers published relating to the filtration of yeast and other particles that may deform, and designs employing slot widths down to 1 micron in diameter (Kuiper et al, 2002).

The entrance and rejection of deformable drops at the entrance to circular pores has been modelled by Nazal and Weisner (1996), Cumming et al (2000) and Spijksma (2004). The behaviour of the drops, and their fate as they pass through the pore, has been considered by Park (2001). In this paper a model of the behaviour of deformable drops and bubbles in a converging slot with liquid flowing into the wide end of the 
slot and out at the narrow side of the slot is developed. This is considered as a first step in the analysis of slotted microfiltration where one might seek to minimise the converging region leading to the minimum slot diameter, to achieve maximum rejection performance.

The analysis of the problem is based on an analogue to oil drops approaching the minimum width of a filtering slot, as illustrated in Figure 1. In order for the drop to pass through the slot, with a slot width less than the drop diameter, the drop must deform from its shape of minimum required energy (i.e. a sphere) and the creation of the new surface area will require energy, hence a force, that must be supplied by the fluid flowing around the drop. The analysis is based on an energy, or force, balance for the process. In the arrangement illustrated in Figure 1 there will be an equilibrium position for the location of the deforming drop, whereby the force required to deform the drop is balanced by the deformation of the drop. The drop will not progress further towards the filtering slot as the force required to deform it further from a sphere is greater than the force provided by the liquid drag flowing over the drop.

\section{Theoretical Estimation of stable equilibrium position}

A drop or bubble is placed in the channel upstream of the converging slot as shown in Figure 1. The liquid is then passed through the slot at a volumetric flow $U$, this will transport the drop into the converging slot until it comes to rest at an equilibrium position. The bottom surface of the slot converges at an angle of $\alpha$. The flow in the slot is assumed to be laminar and equilibrium is achieved when the drag, due to flow over the drop, is balanced by the work done against the bubble capillary force when the bubble has been squeezed. This is shown in Figure 2, where the motion can be 
seen to be stopped when the drag force, $F_{d}$, is balanced by the capillary force, $F_{c}$, acting normally to the slot surfaces and resolved in the x-direction, $F_{c x}$.

When the drop is squeezed it is assumed that its shape can be described by an oblate spheroid with the axis of vertical symmetry being equal to the distance between the slot surfaces at the centre of the drop $(h)$ and its diameter being $D_{\text {ell }}$. When the drop is compressed from its normal spherical shape to an ellipsoid the energy required $\left(E_{c a}\right)$ is the difference between the surface area of a sphere $\left(S_{s p h}\right)$ and an ellipsoid $\left(S_{\text {ell }}\right)$ multiplied by the surface tension $(\sigma)$, for a bubble, or the interfacial tension, for an immiscible drop.

$$
E_{c a}=\sigma\left(S_{e l l}-S_{s p h}\right)
$$

The surface area of a sphere is

$$
S_{s p h}=\pi D_{s p h}^{2}
$$

where $D_{s p h}$ is the sphere diameter.

The surface area of an oblate spheroid is

$$
S_{e l l}=\pi D_{e l l}\left[\frac{D_{e l l}}{2}+\frac{h^{2} \operatorname{arcsinh}\left(\frac{D_{e l l} e}{h}\right)}{2 \mathrm{D}_{\mathrm{ell}} e}\right]
$$

where

$$
e=\sqrt{\frac{D_{\text {ell }}^{2}-h^{2}}{D_{\text {ell }}^{2}}}
$$

As the pressure changes are low the volume of the deforming bubble is assumed to be conserved. So the ellipsoid diameter can be related to the original sphere diameter as:

$$
D_{\text {ell }}=\sqrt{\frac{D_{s p h}^{3}}{h}}
$$

The energy change due to squeezing the bubble is described by the equation: 
$E_{c a}=\left[\int F_{c}(l) d l\right]_{l=D_{s p h}-h}$

So differentiating the energy with respect to $l$ will give the capillary force:

$$
F_{c}=\left[\frac{\partial E_{c a}}{\partial l}\right]_{l=D_{s p h}-h}
$$

Projecting this force on to the $\mathrm{x}$ axis gives:

$$
F_{c x}=\left[\frac{\partial E_{c a}}{\partial l}\right]_{l=D_{s p h}-h} \sin \alpha
$$

After substituting equations (1-4) in to (8), taking into account (5) then the value of the force on the $\mathrm{x}$ direction is:

$$
F_{c x}=\frac{\pi \gamma}{4}\left(\frac{\left(8 D_{s p h}^{4} h-8 D_{s p h} h^{4}-6 D_{s p h}^{5}+3 D_{s p h}^{2} h^{3}\right)}{h\left(D_{s p h}^{3}-h^{3}\right)}+\frac{\sqrt{D_{s p h}} h^{5} \arcsin \left(\frac{\sqrt{D_{s p h}^{3}-h^{3}}}{\sqrt{h^{3}}}\right)}{\sqrt{\left(D_{s p h}^{3}-h^{3}\right)^{3}}}\right)
$$

The case of the drag exerted on a sphere located between two parallel plates has been solved by Keh and Chen (2001). The drag force $\left(F_{d}\right)$ is described by the equation:

$$
F_{d}=k_{w} F_{0}
$$

where $k_{w}$ is the correction factor due to the parallel walls and $F_{0}$ is the drag force on a droplet in an unbounded medium using the analyses of Hadmard (1911) and Rybczynski (1911).

$$
F_{0}=6 \pi \eta r \frac{3 \eta_{d}+2 \eta}{3 \eta_{d}+3 \eta} U
$$

where $r$ is the drop radius, $U$ is the liquid velocity and $\eta_{d}$ and $\eta$ are the viscosities of the drop fluid and the external fluids respectively.

For the three systems investigated in this work the values of $k_{w}$ are as follows:

- Air bubble in paraffin oil, $k_{w}=4.28$ 
- Air bubble in Tween 20 solution, $k_{w}=4.28$

- Paraffin oil in Tween 20 solution, $k_{w}=4.3$

For the case where the drops are not spherical but ellipsoidal. To allow for this the value of $r$ used in equation (11) was that of a drop that would give the same drag as the ellipsoid that is being observed. This was calculated using the analysis described by Happel and Brenner (1965). This gave the following equation:

$$
r=\frac{4 D_{\text {ell }}}{3\left[-\frac{b}{1-b^{2}}-\frac{\left(2 b^{2}-3\right)}{\sqrt{\left(1-b^{2}\right)^{3}}} \arcsin \sqrt{1-b^{2}}\right]}
$$

where $b=h / D_{\text {ell }}$

Applying the equilibrium condition

$F_{d}=F_{c x}$

the solution for the stable location of drops and bubbles can then be calculated using equations (9), (10), (11), (12) and (13). This set of equations gives an analytical solution for the velocity of the liquid $(U)$ for different drop geometries and liquid properties.

\section{EXPERIMENTAL PROCEDURE}

A schematic drawing of the cell used to investigate the behaviour of bubbles and drops in a converging slot is shown in Figure 3. The cell consists of a thick aluminium block $100 \mathrm{~mm}$ long, $40 \mathrm{~mm}$ wide and $25 \mathrm{~mm}$ thick. On top of this block a glass plate $82 \mathrm{~mm}$ long, $20 \mathrm{~mm}$ wide and $5 \mathrm{~mm}$ thick was fixed. The block below the plate was milled as shown to give a channel running along its length. The channel started at one end as a slot $1 \mathrm{~mm}$ deep and $10 \mathrm{~mm}$ wide. It then was formed into a ramp $5 \mathrm{~mm}$ long 
where the channel depth reduced from $1 \mathrm{~mm}$ to $0.1 \mathrm{~mm}$. This geometry gives a convergence angle of $10^{\circ}$. The narrow slot $2.8 \mathrm{~mm}$ long then opened up again to a slot $10 \mathrm{~mm}$ wide and $1 \mathrm{~mm}$ depth.

The experimental arrangement for using the cell is shown in Figure 4. The cell was filled so that a continuous column of liquid passed from one side of the slot to the other as shown in Figure 3 with two visible menisci. A bubble, or drop of immiscible liquid, was then placed in the liquid column at the upstream section of the slot. Applying air pressure by opening Valves 1 and 2 caused a slow and steady flow of the liquid column. This flow would drag the bubble or drop into the ramped section of the cell until it reached an equilibrium position on the ramp where it would cease to move any further, as shown in Figure 5. A video camera captured images of the movement of the bubbles, and the menisci, and these were stored on a computer. A double exposure image showed the movement of a meniscus in a fixed time interval, from which liquid velocity was computed using the known dimensions of the cell. Figure 1 diagrammatically shows a bubble that has come to an equilibrium position on the sloping ramp, which is shown as an observation in Figure 5. The bubble size and the final bubble positions were measured from the photographic images. The diameter of bubbles and drops used in the experiments ranged from 0.1 to $2.6 \mathrm{~mm}$.

The immiscible liquids used were drops of paraffin oil with aqueous Tween 20 solutions as the continuous phase, both chemicals were supplied by Sigma Aldrich. The interfacial tension between paraffin oil and Tween 20 solution was measured using the pendant drop technique. Experiments with air bubbles used either paraffin oil or Tween 20 solution as the continuous phases. The surface tension was measured using the De Nouy ring method. The viscosity of the liquids was measured using a Haake VT 550 Viscometer fitted with a rotating cylinder contained within a 
concentric cup. The density of the liquids was also determined. The values of the measured properties are given in Table 1.

\section{RESULTS AND DISCUSSION}

The experimental measurements of the equilibrium positions of bubbles and drops in the converging slot were determined for air bubbles in paraffin oil, air bubbles in Tween 20 solution and paraffin oil drops in Tween 20 solution. The diameter of the original spherical drops and bubbles was measured and then the equilibrium location on the ramp was determined for different flows. The gap distance $(h)$ between the two surfaces trapping the drop, or bubble, was calculated for the centre of the ellipsoid. From the flow of liquid in the cell $(Q)$ the average velocity past the drop or bubble was calculated using the equation:

$$
U=\frac{Q}{a_{s} h^{2}-\frac{\pi h D_{\text {ell }}}{4}}
$$

where $a_{s}$ is the ratio of the slot width to the slot height.

The comparison between the experimental measured equilibrium locations and those estimated using the model described in this paper are shown in Figure 6. The predictions being made use the fundamental properties of the fluids and the geometry of the experimental cell. The comparison between the experimental measurements and the predictions can be seen to be good. For the liquids used, the interfacial tensions varied by up to a factor of eight and the viscosity varied by a factor of five over the range of experimental data.

The model predictions represented by curves on Figure 6 indicate the equilibrium position of a drop or bubble and its deformation within the converging slot at differing local velocities. As a drop approaches a converging slot it is slowly squeezed as it moves along the narrowing slot so that the ratio of the original drop diameter to the slot width increases until the equilibrium location is reached where the forces generated by the squeezing of the drop balance those due to drag produced by liquid flowing past the drop

When a drop or bubble reaches the top of the converging slot it will no longer be trapped but will pass into the wider downstream section of the test cell. As might be expected the ease with which the drop or bubble is deformed is determined by the 
surface, or interfacial, tension. This is clearly shown in Figure 6 by the lower surface energy drops and bubbles being squeezed more easily by the interaction of the converging slot and the liquid flowing past them, so the drop deformation described by the ratio of $D / h$ is much greater for similar local velocities.

The objective of this work was to begin to understand the behaviour of deformable drops at a slotted microfilter. This is of interest because a drop located within a slot experiences different forces to a drop located on a round pore. In the case of a slot the force causing it to move through the slot originates from the liquid drag produced by the flow round the drop resting at the membrane surface. In the case of a circular pore, drops larger than the pore will completely block off the pore and their transport through the pore is driven by the total pressure drop across the filter. An analysis of drop passage through a circular pore membrane has been presented previously (Cumming et al ????). The analysis presented here is for the case of drops within a converging slot, which is being used to determine the force required to drag an oil drop through a slotted microfilter.

An example of a converging slot microfilter is illustrated in Figure 7. These filters are produced by a photolithographic technique, which provides a small converging section prior to the position of minimum slot width. This type of filter is commercially available from Micropore Technologies Ltd. and is being evaluated for the filtration of oil drops from PW. One side of the filter has a much more prominent conical region prior to the minimum slot width and the following analysis is based on this prominent side facing the challenge suspension to be filtered. To determine the flux through the slotted microfilter the pores were assumed to be $420 \mu \mathrm{m}$ long and three different minimum slot widths were used for the calculations: $1 \mu \mathrm{m}, 5 \mu \mathrm{m}$ and $10 \mu \mathrm{m}$. The slot density was taken as $9.2 \times 10^{6}$ slots $\mathrm{m}^{-2}$ and the flux was calculated as the permeate flow for a square metre of filter area. The first drop reaching the membrane surface will either sit at the slot entrance, take up a stable position within the converging slot or it will pass all the way through the converging slot and eventually pass out the other side into the filtrate. The fate of the drop being determined by geometry and physical properties of the fluids involved. The slots were measured as converging at a half-angle of $34^{\circ}$. The oil properties were taken to be kerosene dispersed in water. The flux at which the model predicts that drops of different sizes will pass through filters of different slot widths is shown in Figure 8. 
As might be expected drops that are of the same size as slot width, or smaller, pass straight through the filter. However, drops only slightly larger than the slot width will pass through the filter at relatively low fluxes. As the flux is increased larger drops begin to pass through the filter as they are increasingly deformed by the converging slot. As the drops deform to an ellipsoidal shape the drag on them increases as their projected area normal to flow becomes greater. As can be seen from Figure 8, this means that eventually the smaller slot will give passage to larger drops than would be passed by a membrane with wider slots. This is partly due to the increasing drop deformation, but is also a consequence of the fact that the narrower slots will have a much larger local liquid velocity past the drops for the same liquid flux rate when using a fixed number of pores per unit area. Hence, the liquid drag will be greater when filtering using the smaller slot width filters.

The prediction shown in Figure 8 is supported by the data illustrated in Figure 9, which is the oil drop rejection (or grade efficiency) curve for a slotted pore microfilter with minimum slot width of 5 microns filtering a crude oil dispersion at a challenge concentration of ??? $\mathrm{mg} \mathrm{L}^{-1}$. The permeate flux rate was $1000 \mathrm{~kg} \mathrm{~m}^{-2} \mathrm{~h}^{-1}$ and the filter provides $100 \%$ oil drop rejection at 8 microns, which is close to what is predicted using the theory illustrated in Figure 8.

\section{CONCLUSIONS}

Microfiltration using slotted pore filters is being actively pursued for many process applications including that of the removal of oil drops from Produced Water. This is a non-intuitive application, as it may be assumed that oil drops would deform easily and pass through a pore that has a highly non-isotropic shape. Thus, intuition might suggest that a circular pore membrane is preferable for the filtration of oil drops. However, previous work has shown that stable fluxes of only up to $200 \mathrm{l} \mathrm{m}^{-2} \mathrm{~h}^{-1}$ have been possible when filtering with circular pore membranes, and obtaining reasonable oil rejection efficiency. Whereas when filtering with slotted pore microfilters fluxes of up to $20001 \mathrm{~m}^{-2} \mathrm{~h}^{-1}$, whilst operating under similar experimental conditions, can be achieved. 
The main reason for the difference between the performance of the slotted and circular pore membranes is the difference in the mechanism of passage of the oil drop into the permeate. An oil drop sitting on a circular pore membrane will experience the full pressure difference between the feed and permeate side of the membrane. This will act to push the oil drop into the pore and, possibly, through the membrane into the permeate. However, with a slotted pore membrane in which the concentration of oil drops is sufficiently low as not to completely plug the pore with an assemblage of oil drops, the mechanism of passage of the oil drop into the permeate is that of liquid drag of the permeate flowing around the drop. This is because the spherical oil drop does not completely block the flow of liquid flowing through the slotted filter pore. Thus, oil drop passage depends on the permeate liquid flow rate and the ability of the spherical drop to deform within the slotted pore channel.

The mathematical analysis presented here is based on a force balance, used to determine the liquid drag and the force required to deform the drop from a sphere into an oblate spheroid. In the experimental techniques described a converging slot was employed in order to investigate the position at which these two forces balance, with observation by video camera providing the experimental data. The mathematical analysis was compared to the observed data, obtained for fluids of a variety of interfacial tensions and liquid viscosities, and the agreement between the predicted and measured values was found to be very good.

The modelling approach has uses in determining the ability of a slotted microfilter to completely reject an oil drop, for a given permeate flow rate. Comparison for slotted microfilters with three different pore widths is shown, illustrating the point that better oil drop rejection is possible with a wider diameter slotted pore than a narrower one, under operating conditions of very high permeate flux rates. Comparison with 
experimental data for the slotted pore microfiltration of a crude oil using a 5 micron pore width filter shows a $100 \%$ rejection of oil drops at 7 microns, whereas the model predicts total rejection at 8 microns whilst operating at a flux rate of $1000 \mathrm{~kg} \mathrm{~m}^{-2} \mathrm{~h}^{-1}$ in both cases. The closeness of these values supports the modelling approach and the use of the model to assist in the design of slotted pore microfilters for use on drops that can deform in the filtration process.

\section{ACKNOWLEDGEMENT}

The authors wish to thank the Engineering and Physical Sciences Research Council of the UK for an award (GR/S04758/01) which partially supported the work described here.

\section{LIST OF SYMBOLS}

A surface area of the resin bead, $\quad \mathrm{m}^{2}$

$b \quad$ Langmuir isotherm model parameter, $\quad \mathrm{ppm}^{-1}$

$C \quad$ concentration in the solution (both in cell and at the exit), $\quad$ ppm

$C_{\text {eq }}$ equilibrium boron concentration in the liquid phase, ppm

$C_{\text {feed }}$ concentration in the feed to the cell, $\quad$ ppm

$C^{*} \quad$ equilibrium boron concentration at the surface of the resin, $\quad \mathrm{ppm}$

$D_{\text {eff }} \quad$ effective diffusion coefficient of boron inside the particle, $\quad \mathrm{m}^{2} \mathrm{~s}^{-1}$

$D_{\text {liq }} \quad$ diffusion coefficient of the boron in the bulk liquid phase, $\quad \mathrm{m}^{2} \mathrm{~s}^{-1}$

$F$ feed flow rate, $\quad \mathrm{m}^{3} \mathrm{~s}^{-1}$

$k$ mass transfer coefficient in the liquid phase, $\mathrm{m} \mathrm{s}^{-1}$

$m \quad$ mass of resin in the cell, $\quad \mathrm{kg}$

$q \quad$ boron concentration on the resin particles, $\quad \mathrm{g} \mathrm{g}^{-1}$ 
$\bar{q} \quad$ average mass of boron per mass of resin, $\quad \mathrm{g} \mathrm{g}^{-1}$

$q_{\max } \quad$ maximum capacity of the resin particle, $\quad \mathrm{g} \mathrm{g}^{-1}$

$R$ bead radius, $\quad \mathrm{m}$

$r \quad$ radial position inside the particle, $\quad \mathrm{m}$

$t$ time, $\quad \mathrm{s}$

$V \quad$ liquid volume in the cell, $\quad \mathrm{m}^{3}$

$V_{\text {resin }} \quad$ resin particle volume, $\quad \mathrm{m}^{3}$

$x \quad$ diameter of the resin particle, $\quad \mathrm{m}$

Greek

$\delta \quad$ film thickness, $\quad \mathrm{m}$

$\mu \quad$ liquid viscosity, $\quad \mathrm{kg} \mathrm{m}^{-1} \mathrm{~s}^{-1}$

$\rho \quad$ liquid density, $\quad \mathrm{kg} \mathrm{m}^{-3}$

$\rho_{s} \quad$ density of the particle, $\quad \mathrm{kg} \mathrm{m}^{-3}$

\section{REFERENCES}

Cumming, I.W., Holdich, R.G. and Smith, I.D. (2000), The rejection of oil by microfiltration of a stabilised kerosene/water emulsion, J. Membrane Sci. 169, 147155.

Hadamard, J.S. (1911) Movement permanent lent d'une sphere liquide et visqueuse dans un liquide visqueux, Comptes Rendus Hebdomadaires des Seances de V A cagdemie des Sciences(Paris), 152, 1735-1738T

Hargreaves, J.H. and Silvester, R.S. (1990). Computational fluid dynamics applied to the analysis of deoiling hydrocyclone performance, Trans. I. Chem. E., 68, 365-383. 
Happel, J and Brenner, H. (1965) Low Reynolds Number Hydrodynamics, Prentice Hall,

Holdich, R.G., Cumming, I.W. and Smith, I.D. (1998), Crossflow microfiltration of oil in watr dispersions using surface filtration with imposed fluid rotation, J. Membrane Sci., 143, 263-274.

International Maritime Organization, The Paris Convention 1974 and the Oslo Convention 1972, OSPAR, 4 Albert Embankment, London, (UK).

Keh, H.J. and Chen, Po Y. (2001). Slow motion of a droplet between two parallel walls, Chem. Eng. Sci., 56, 6863-6871

Koltuniewicz, A.B., Field, R.W. and Arnot, T.C. (1995), Cross-flow and dead-end microfiltration of oily-water emulsion. Part 1: Experimental study and analysis of flux decline. J. Membrane Sci., 102, 193-207.

Koltuniewicz, A.B. and Field, R.W. (1996), Process factors during removal of oil-inwater emulsions with cross-flow microfiltration, Desalination, 105, 79-89.

Kuiper, S., van Rijn, C., Nijdam, W., Raspe, O., van Wolferen, H., Krijnen, G. and Elwenspoek, M. (2002), Filtration of lager beer with microsieves: flux, permeate haze and in-line microscope observations. J. Membrane Sci., 196, 159-170 
Lin, S.H. and Lan, W.J. (1998), Waste oil/ water treatment by membrane processes, J. of Hazardous Materials, 59, 189-199.

Lipp, P., Lee, C.H., Fane , A.G. and Fell, C.J.D. (1988), A fundamental study of the ultrafiltration of oil-water emulsions, J. Membrane Sci., 36, 161-177.

Madeni, S.S. and Yeganeh, M.K. (2003), J. of Porous Materials, (10), 131-138.

Mueller, J., Cen, Y.W. and Davis, R.H. (1997), Crossflow microfiltration of oily water, J. Membrane Sci., 129(2), 221-235.

Nazal, F.F. and Weisner, M.R. (1996), Microfiltration oil-in-water emulsions, Water Environ. Res., 68, 1187-1191.

Park, S-H, Yamaguchi, T. and Nakao, S-i. (2001), Transport mechanism of deformable droplets in microfiltration of emulsions, Chem. Eng. Sci., 56, 3539-3548.

Rautenbach, R and Albrecht, R.(1989), Membrane Processes, Wiley, Chichester, (UK).

Rybvzynski, W,(1911). Uber die Fortschreitende Bewegung einer flussigen Kugel in einem zahen Medium, Bull. Acad. Sci. Cracovie Ser. A, 1, 40-46

Spijksma, G.I., Benes, N.E. and Blank, D.H.A. (2004), Membrane separation of liquid-like droplets, Sep. and Pur, Tech., 40, 103-108. 
Wang, P., Xu, N. and Shi, J. (2000), A pilot study of the treatment of waste rolling emulsion using zirconia microfiltration membranes, 173, 159-166. 


\section{List of Tables}

Table $1 \quad$ Physical properties of the liquids used in the tests

\section{List of Figures}

Figure 1 Schematic diagram of drop in converging slot and its deformation from a spherical shape

Figure 2 Deforming drop at the equilibrium position

Figure 3 Converging slot experimental cell: a) side elevation b) plan view

Dimensions in $\mathrm{mm}$ and not drawn to scale

Figure 4 Schematic diagram of the experimental arrangement for the slot experiments

Figure 5 Looking down on a bubble come to rest on the ramp with a graticule on the top glass surface with divisions at every ?? $\mathrm{mm}$

Figure 6, Comparison between model and experimental data for the ratio of drop diameter to channel height against liquid velocity flowing past the stationary drop

Figure 7 Image of a commercially available slotted microfilter showing conical lead in to the minimum slot width in one orientation of the membrane 
Figure 8 Predicted size of drop passing through a converging slotted membrane at three slot widths using the same number of slots per unit area for each filter with superficial permeate flux rate

Figure 9 Grade efficiency when filtering crude oil on a 5 micron slotted pore microfilter at a permeate flux rate of $1000 \mathrm{~kg} \mathrm{~m}^{-2} \mathrm{~h}^{-1}$ illustrating complete oil drop rejection at ?? micrometres 
Table 1 Physical properties of the liquids used in the tests

\begin{tabular}{|l|c|c|c|}
\hline Liquid & $\begin{array}{c}\text { Interfacial tension, } \\
\mathrm{mN} / \mathrm{m}\end{array}$ & $\begin{array}{c}\text { Liquid viscosity } \\
\mathrm{Pa} \mathrm{s}\end{array}$ & $\begin{array}{c}\text { Liquid density } \\
\mathrm{kg} / \mathrm{m}^{3}\end{array}$ \\
\hline Paraffin oil/Air & 29 & 0.08 & 790 \\
\hline Tween 20/Air & 39 & 0.40 & 1110 \\
\hline Paraffin oil/ Tween 20 & 5 & & \\
\hline
\end{tabular}




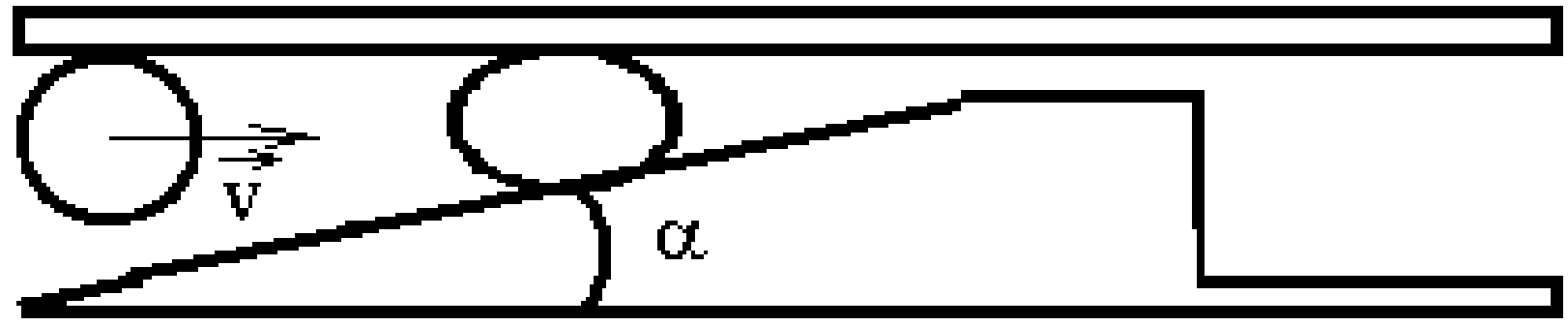

Figure 1 Schematic diagram of drop in converging slot and its deformation from a spherical shape 


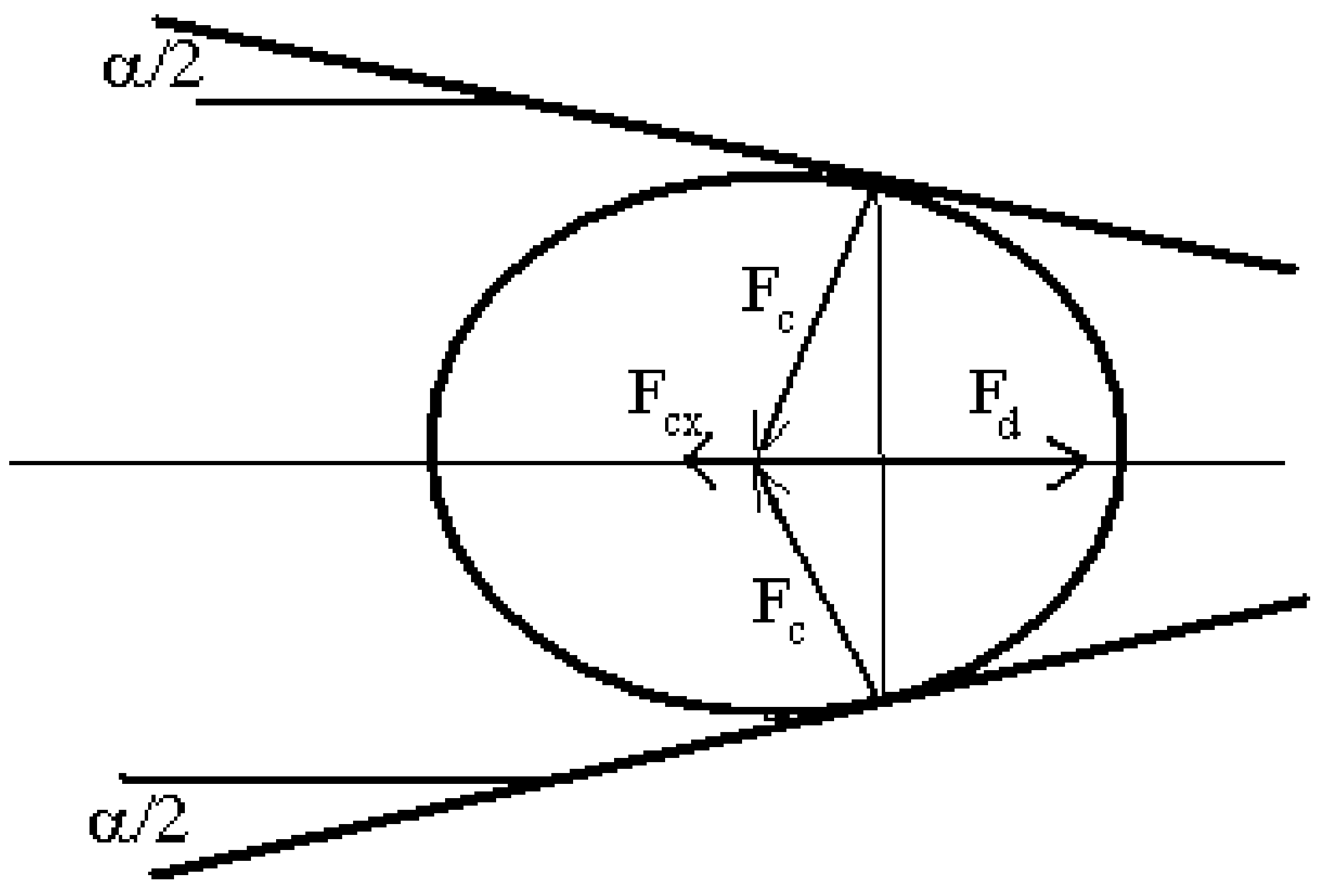

Figure 2 Deforming drop at the equilibrium position 


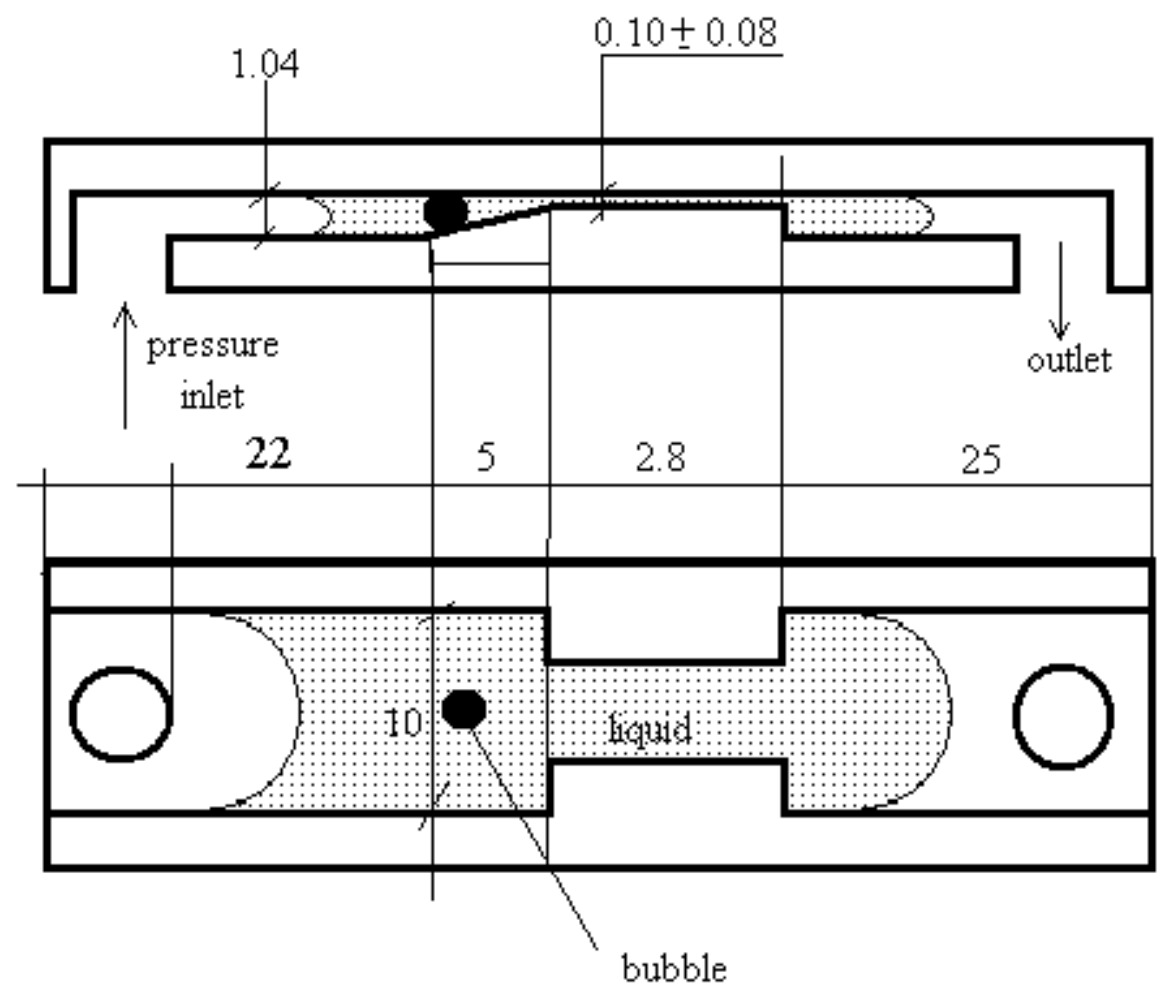

Figure 3 Converging slot experimental cell: a) side elevation b) plan view Dimensions in $\mathrm{mm}$ and not drawn to scale 


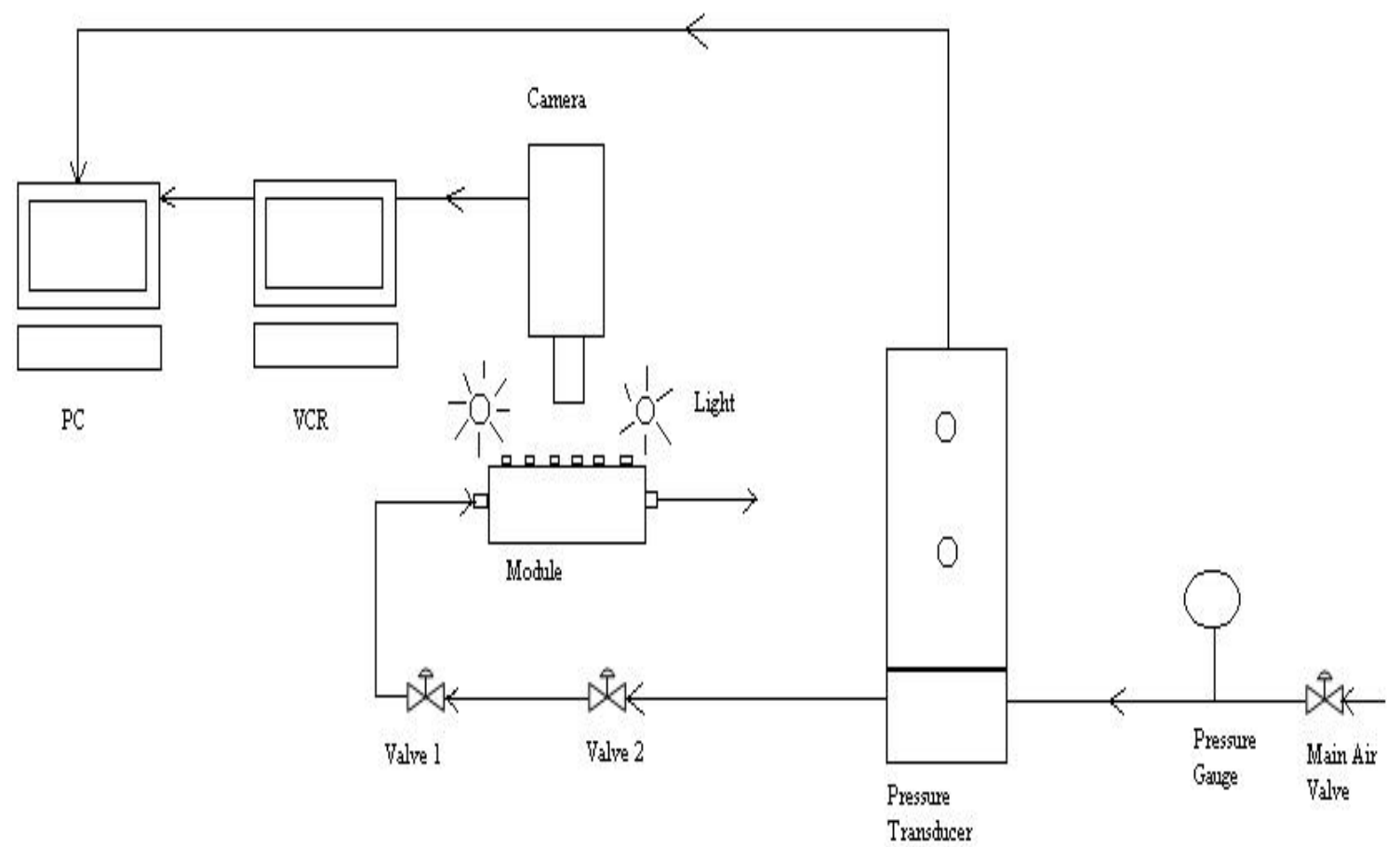

Figure 4 Schematic diagram of the experimental arrangement for the slot experiments 


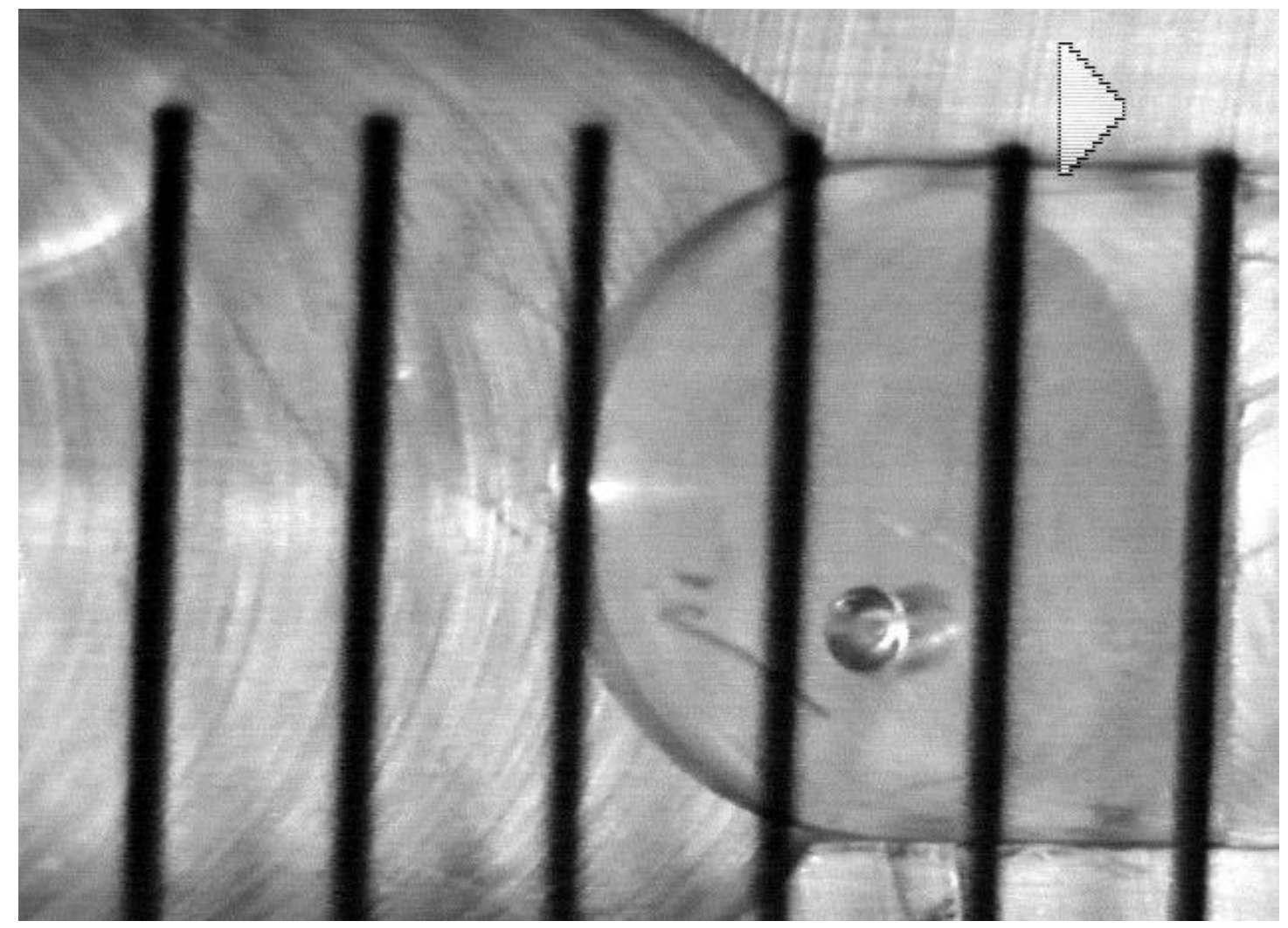

Figure 5 Looking down on a bubble come to rest on the ramp with a graticule on the top glass surface with divisions at every ?? $\mathrm{mm}$ 


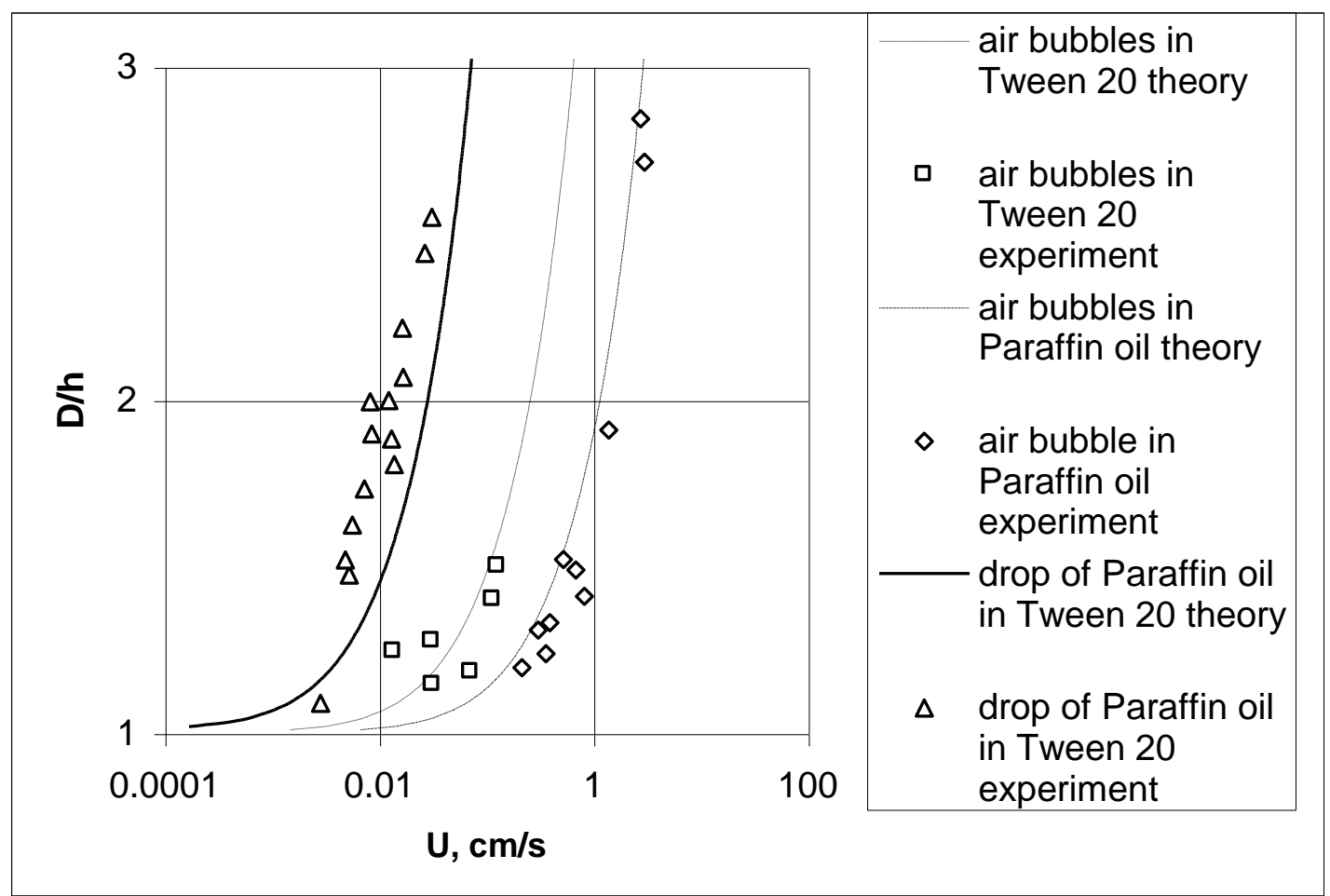

Figure 6, Comparison between model and experimental data for the ratio of drop diameter to channel height against liquid velocity flowing past the stationary drop 


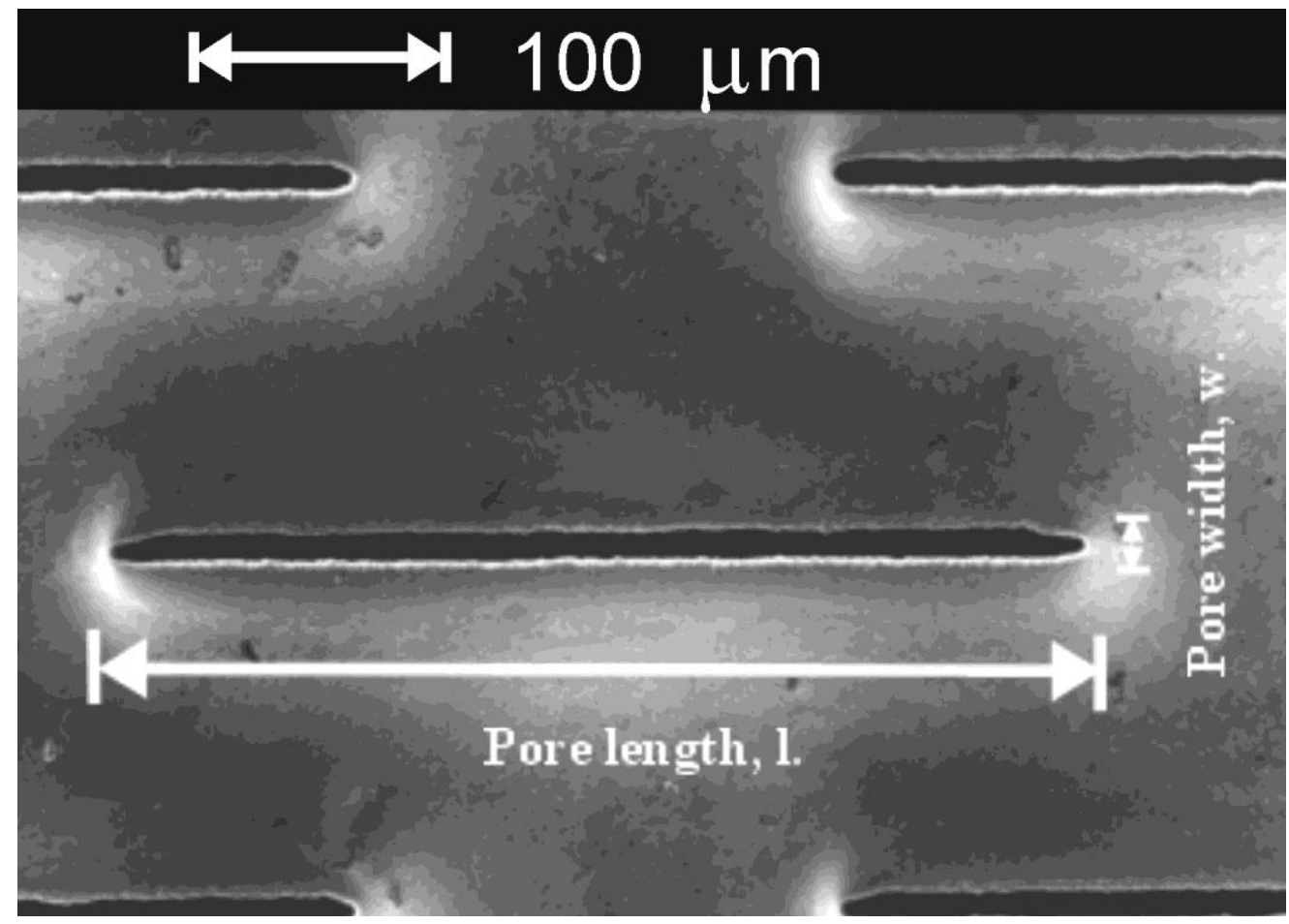

Figure 7 Image of a commercially available slotted microfilter showing conical lead in to the minimum slot width in one orientation of the membrane 


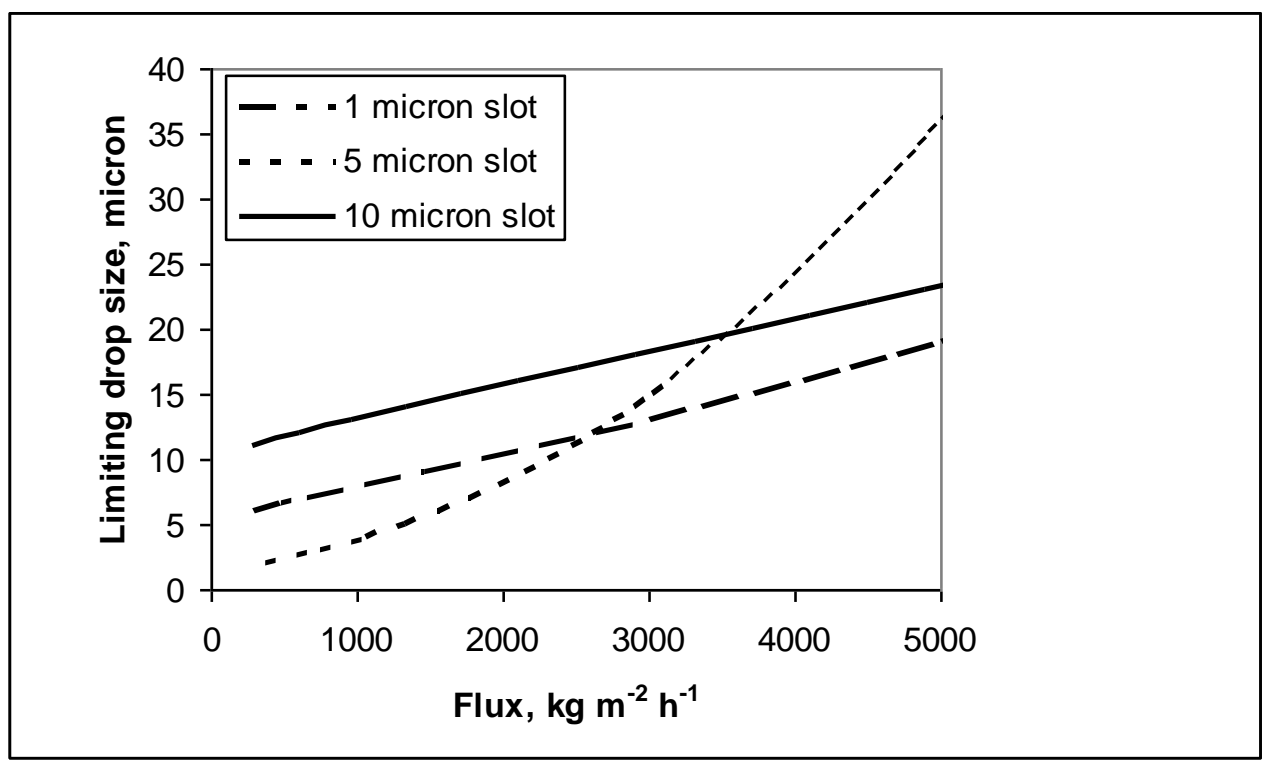

Figure 8 Predicted size of drop passing through a converging slotted membrane at three slot widths using the same number of slots per unit area for each filter with superficial permeate flux rate 


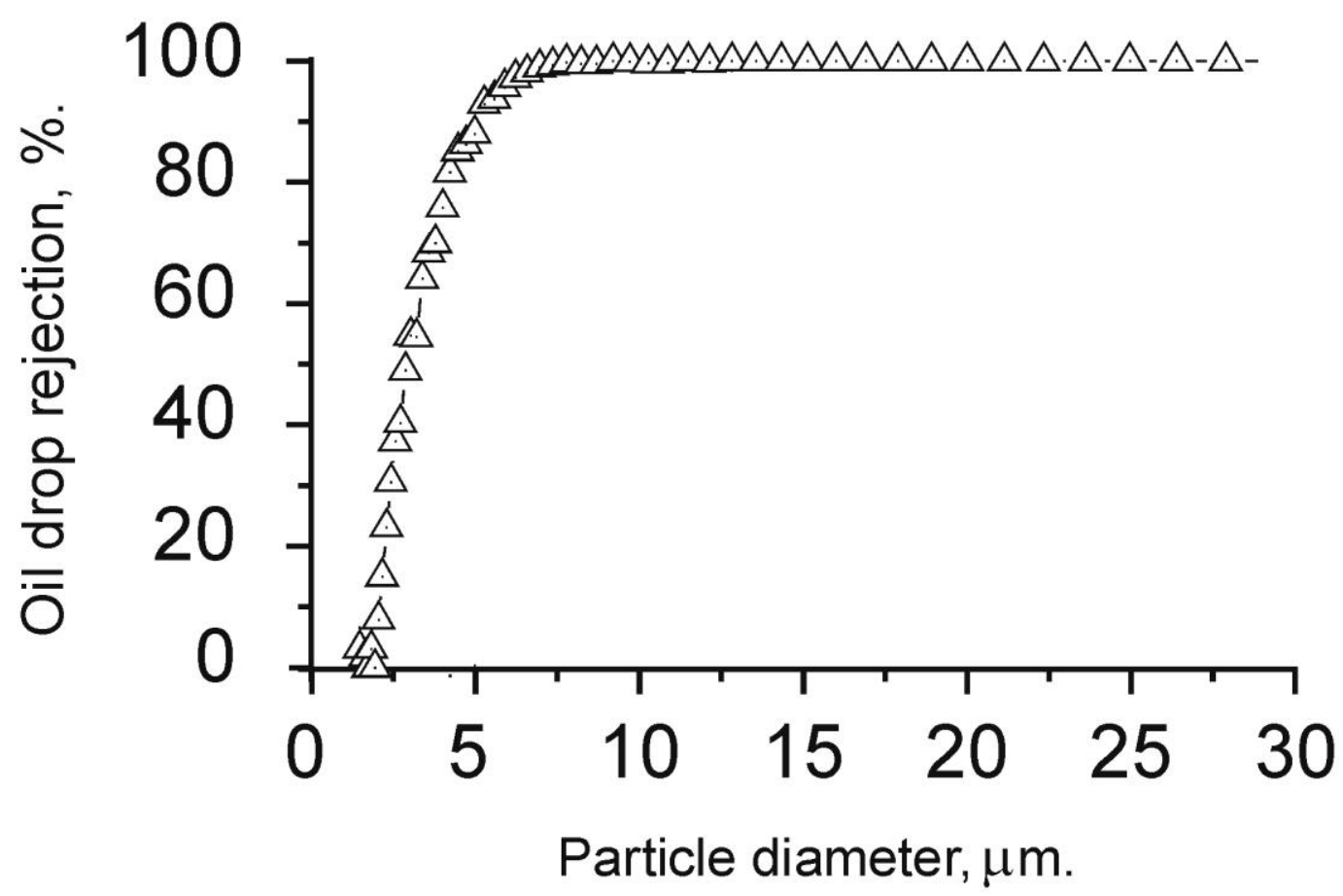

Figure 9 Grade efficiency when filtering crude oil on a 5 micron slotted pore microfilter at a permeate flux rate of $1000 \mathrm{~kg} \mathrm{~m}^{-2} \mathrm{~h}^{-1}$ illustrating complete oil drop rejection at 7 microns 